\title{
Democratización del Arbitraje en el Perú
}

Jenny Díaz Honores

Abogada por la Universidad San Martin de Porres. Estudios de maestría en Derecho Civil y Comercial en la Universidad Nacional Federico Villarreal.

Maestría en Derecho Civil por la Universidad Alas Peruanas. Egresada del programa de Arbitraje Comercial Internacional en American University Washington College of Law.

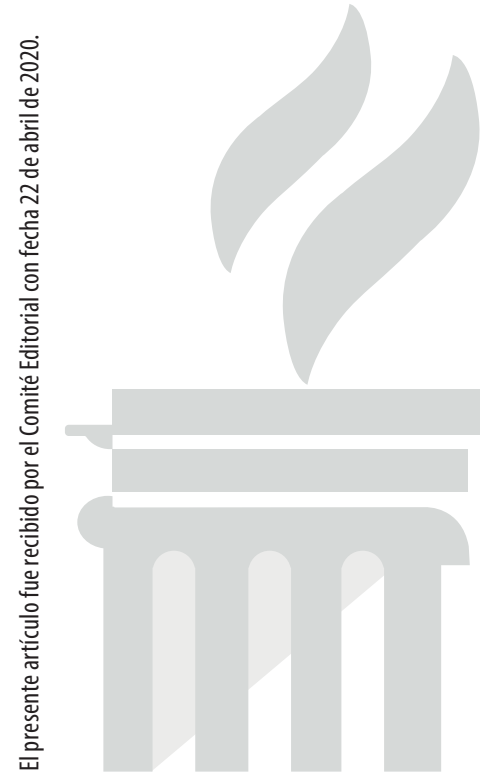

SUMARI0:

I. Introducción.

II. Antecedentes y evolución del Arbitraje.

III. Democracia y Arbitraje.

IV. Arbitraje popular.

V. Arbitraje en Consumo.

VI. Arbitraje en Salud.

VII. Conclusiones. 


\section{RESUMEN:}

El presente artículo tiene como finalidad destacar el desarrollo de los mecanismos alternativos de solución de conflictos en nuestro país a consecuencia de la crisis de los tribunales judiciales y del alto costo económico y emocional del arbitraje. De esta manera, se explican cuáles son los instrumentos que ha implementado el Estado en favor de los sectores sociales más vulnerables para garantizar que toda la población tenga acceso a la justicia arbitral.

Palabras clave: mecanismos alternativos, arbitraje, acceso a la justicia, democracia, laudo arbitral, equidad.

\footnotetext{
ABSTRACT:

The purpose of this article is to highlight the development of alternative dispute resolution mechanisms in our country as a result of the crisis in the judicial courts and the high economic and emotional cost of arbitration. In this way, it explains the instruments that the State has implemented in favor of the most vulnerable social sectors to guarantee that the entire population has access to arbitration justice.

Keywords: alternative mechanisms, arbitration, access to justice, democracy, arbitration award, equity.
}

\section{INTRODUCCIÓN}

Los mecanismos alternativos de solución de conflictos, también conocidos como MASC, como la conciliación extrajudicial o el arbitraje, son procedimientos basados en el principio de la autonomía de la voluntad de las partes cuyo objetivo principal es la solución de los conflictos y tienen como características comunes la flexibilidad, autodeterminación, economía, rapidez y confidencialidad en comparación con los procesos judiciales. Los MASC, debido a las ventajas que ofrecen a los ciudadanos, han tomado una posición importante en los sistemas de justicia por su contribución a promover formas pacificas de solución de conflictos interpersonales.

La institucionalización de los MASC surge como consecuencia de la crisis de los tribunales judiciales, el descontento ciudadano con las decisiones de los jueces, la lentitud procesal, burocratización de la justicia y los altos riesgos de corrupción en la administración de la justicia.

La finalidad de los MASC, como la conciliación y el arbitraje, es que los conflictos de las personas sean resueltos con un menor costo económico, tiempo, desgaste emocional y con un mejor resultado para las partes; así como apoyar a la justicia ordinaria y fomentar la participación directa de las partes en la resolución de sus problemas. Así por ejemplo, la conciliación extrajudicial - como MASC - puede contribuir en evitar la congestión desmesurada de los despachos judiciales si es que a través de estos mecanismos se resuelven los conflictos de mínima complejidad; de otro lado, el arbitraje se convierte en una alternativa a conflictos tanto complejos como simples o que requieren de una resolución rápida al problema.

El arbitraje en el Perú es un mecanismo extrajudicial de solución de conflictos elegido o impuesto por la Ley a las partes, con la finalidad que un tercero neutral, independiente e imparcial, designado de forma directa o indirecta por las partes, resuelva una controversia de forma definitiva y vinculante. La resolución final -laudo-que emite un tribunal arbitral, sea árbitro único o colegiado tiene según el Decreto Legislativo 1071 mérito de cosa juzgada; es decir, tiene el mismo valor legal que una sentencia judicial firme, con la diferencia que en el proceso judicial la sentencia judicial puede ser apelable para que lo resuelto por el juez sea revisado por una instancia superior; en cambio, en el arbitraje, el laudo es por Ley inapelable y, por tanto, es de obligatorio cumplimiento y ejecutable una vez emitido.

Si bien los antecedentes del arbitraje en el Perú se remontan desde la etapa colonial con la llegada de la legislación española, es a partir de la década de los 1990 que el arbitraje en el Perú toma un impulso legislativo real para su utiliza- 
ción y empleo como mecanismo extrajudicial de solución de conflictos alternativos al proceso judicial, pues, con anterioridad a este periodo, la elección y utilización del arbitraje era prácticamente inexistente para la comunidad jurídica y aún más para la sociedad peruana.

El objetivo del arbitraje es resolver controversias que versen sobre derechos disponibles de las partes o para aquellas pretensiones que nuestra legislación autorice expresamente. Lo interesante desde el punto de vista jurídico es como ya señalamos antes, si un tribunal arbitral resuelve una controversia, la decisión adoptada es inapelable y adquiere la calidad de cosa juzgada, es decir, es de obligatorio cumplimiento para las partes que sometieron la resolución de su conflicto a la decisión del árbitro.

Han transcurrido más de 27 años desde la dación de la primera ley de arbitraje en el Perú, que fue aprobada por el Decreto Ley $25935^{1}$ y que marca un hito, un antes y después, entre el régimen de arbitraje anterior regulado hasta ese momento en el Código de Enjuiciamiento Civil de 1912, el Código Civil de 1984 y en el Código Procesal Civil de 1993, con el régimen arbitral actual regulado en el Decreto Legislativo 1071, que representa una legislación moderna sobre el arbitraje al recoger muchas de las disposiciones del modelo UNCITRAL ${ }^{2}$ - United Nations Commission On International Trade Law-, brindándole autonomía procesal frente a la normatividad sobre el proceso civil peruano e independencia en el ejercicio de la función arbitral de los tribunales arbitrales y señalando expresamente la prohibición de la injerencia judicial una vez instalado el arbitraje.
En este orden de ideas, y a más de dos décadas y media de la expedición de la primera ley de arbitraje, resulta relevante comentar y analizar la evolución legislativa del arbitraje en el Perú y el proceso de democratización de este mecanismo extrajudicial de solución de controversias. Si bien su empleo fue exclusivo de ciertas élites económicas y empresariales, y por qué no decirlo, tantas veces excluyente de la mayoría de la población peruana, hoy su acceso, elección y empleo es una realidad para todos.

\section{ANTECEDENTES Y EVOLUCIÓN DEL AR- BITRAJE}

Los antecedentes del arbitraje en el Perú se registran desde la etapa colonial con la llegada de la legislación española y en la etapa republicana con los Códigos de Santa Cruz de 1836, el Código de Enjuiciamientos en Materia Civil de 1852, el Código de Enjuiciamiento Civil de 1912, el Código Civil de 1984, en el Código Procesal Civil de 1993, Ley General del Arbitraje del año 1992, aprobada por Decreto Ley 25935, y la Ley General de Arbitraje del año 1996, aprobada por Decreto Ley $26572 .^{3}$

De otro lado, los antecedentes constitucionales del arbitraje se encuentran desde la Constitución Política de Cádiz de 1812, la Constitución de Huancayo de 1839, la Constitución de 1920, la Constitución de 1979, hasta nuestra Constitución vigente de 1993. Es así, que en la actualidad el arbitraje en el Perú como mecanismo extrajudicial de solución de conflictos forma parte del sistema jurídico de administración de justicia desde el año 1992; además, la juris-

1. El 9 de diciembre de 1992 se expide el Decreto Ley 25935, que aprueba la primera ley de arbitraje en el Perú y que deroga el régimen arbitral anterior contenido en el Código de Procedimientos Civiles de 1912 y en el Código Civil de 1984 .

2. La Comisión de las Naciones Unidas para el Derecho Mercantil Internacional —CNUDMI— es un órgano subsidiario de la Asamblea General. Prepara textos legislativos internacionales para ayudar a los Estados a modernizar el derecho mercantil y textos no legislativos para facilitar las negociaciones entre las partes en operaciones comerciales. Uno de esos textos es la ley modelo de arbitraje sobre la que se ha basado nuestra ley actual de arbitraje.

3. Medardo Nizama Villadolid, «Historia y Desarrollo Del Arbitraje en el Perú», Revista Jurídica Docentia Et Investigatio Vol. 13. N 1. (2011): 82-85. 
dicción arbitral está reconocida expresamente por el artículo 139, inciso 1, de nuestra Carta Magna. Incluso el Tribunal Constitucional en reiteradas jurisprudencias vinculantes ha establecido y, por tanto, dejado de lado el debate académico en nuestro país, sobre la existencia de la jurisdicción arbitral que es autónoma e independiente.

En la actualidad, el arbitraje se encuentra regulado por el Decreto Legislativo 1071 aprobado en el año 2008 —en adelante, Ley de Arbitraje o LA - . Sin embargo, también existen leyes especiales que regulan determinados tipos de arbitraje, como por ejemplo la Ley y Reglamento de Contrataciones con el Estado, que tiene regulaciones particulares para las actuaciones arbitrales al tratarse de controversias en materia de contrataciones públicas.

Definitivamente el arbitraje en el Perú ha evolucionado respecto a la forma de someterse a uno, a las materias que se pueden someter a este mecanismo de solución de conflictos, así como a su regulación y la independencia de las decisiones de los árbitros en sus actuaciones frente a la posible interferencia judicial.

Es así, por ejemplo, que el Código Civil promulgado por el Decreto Legislativo 295 reguló y desarrolló el arbitraje en su Libro VII —Fuentes de las Obligaciones-, Titulo XI de la Cláusula Compromisoria y compromiso arbitral, del artículo 1906 al 1922, artículos derogados por la Primera Disposición Final del Decreto Ley 25935, Ley General de Arbitraje publicada el 10 de diciembre del año 1992. Antes de la derogación de los artículos 1906 al 1908 del Código Civil que regulaban el arbitraje, para que las partes puedan someterse al arbitraje debían primero tener un acuerdo - cláusula compromisoria- de celebrar en el futuro un compromiso arbitral $^{4}$; pero si el compromiso no fuera formalizado voluntariamente o no lo hubiera hecho el juez a solicitud de parte, para la ratificación del acuerdo, la designación de los árbitros y la determinación del asunto controvertido, la cláusula compromisoria quedaba sin efecto. Es decir, la eficacia de la activación del arbitraje estaba condicionada a un nuevo acuerdo que ratifique el acuerdo inicial o preliminar de recurrir al arbitraje en caso surjan controversias en el contrato principal.

Con la primera Ley General de Arbitraje hubo un avance significativo en el sistema arbitral peruano, pues no solo derogaba las estipulaciones de arbitraje contenidas en el Código Civil, sino que regulaba por primera vez el convenio arbitral como el acuerdo escrito de las partes para someter sus controversias a la decisión de los árbitros, es decir, como acuerdo único y valido para recurrir a la jurisdicción arbitral. Sin embargo, ante la falta de acuerdo entre las partes para la designación del árbitro o árbitros, el nombramiento era judicial, lo que en muchos casos generó una demora o dilación en la elección judicial del árbitro debido a lo engorroso y burocrático que resultan ser los procesos judiciales. ${ }^{5}$ Felizmente, esto fue superado por la actual y vigente Ley de Arbitraje, que determina que a falta de acuerdos sobre la designación de los árbitros y tratándose de un arbitraje ad hoc, las partes deberán recurrir a la Cámara de Co-

4. Artículo 1909.- "Por el compromiso arbitral dos o más partes convienen que una controversia determinada, materia o no de un juicio, sea resuelta por tercero o terceros a quienes designan y a cuya jurisdicción y decisión se someten expresamente." -artículo derogado-.

5. Comentario aparte, pero resuelta interesante el hecho que la comentada ley derogada contemplaba la figura de la sumisión al arbitraje ante el juez civil, básicamente en dos supuestos: a) cuando hay convenio, pero no árbitro designado ni sometimiento a un reglamento arbitral y se requiere integrar el contenido del convenio como por ejemplo en el caso que no se detalle la controversia o la designación del árbitro, y b) cuando no hubiera convenio arbitral y la controversia versa sobre un contrato de naturaleza comercial. De otro lado, si en el convenio arbitral se ha designado árbitro o institución arbitral organizadora, pero no se precisa controversia o carezca de otros requisitos, será el árbitro o la institución quien resuelva la sumisión. 
mercio del lugar del arbitraje, lo que constituye un importante avance en el sistema arbitral que garantiza la celeridad para la instalación del arbitraje. $^{6}$

En este orden de ideas, podemos advertir que el arbitraje en el Perú ha evolucionado positivamente desde la forma de cómo pactar el arbitraje entre las partes, la no interferencia del Poder Judicial en algunas actuaciones arbitrales como en la designación de los árbitros, hasta el valor y efectos del laudo, que hoy en día es inapelable y tiene efectos de cosa juzgada. Podemos decir que la actual Ley de Arbitraje en el Perú es una norma moderna, que busca garantizar la autonomía de la voluntad, pero también la economía y celeridad en las actuaciones arbitrales, permitiendo que el arbitraje sea un mecanismo realmente accesible para los ciudadanos y empresarios.

\section{DEMOCRACIA Y ARBITRAJE}

El término democracia no es ajeno al ciudadano, es un término sencillo y común empleado muchas veces en el desarrollo de nuestras relaciones sociales. Parafraseando a la Real Academia Española, la democracia es una doctrina política o forma de organización social, basada en que la ciudadanía tiene el poder de decisión. Etimológicamente, la palabra democracia proviene del griego democratía, que se compone de los términos démos, que significa 'pueblo', y krátos, que significa 'poder'. Así, la democracia es el gobierno del pueblo.

En la actualidad el término democracia es extensivo a todo grupo social, familiar, empresarial, vecinal, comunidades o grupos organizados en general donde todos los individuos participan en la toma de decisiones de manera participativa y horizontal. Conforme lo mani- fiesta la Organización de Naciones Unidas, la democracia está estrechamente vinculada al ejercicio de los derechos humanos y las libertades fundamentales. Por consiguiente, a través de ella los individuos participan en las decisiones que afectan a sus vidas.

El arbitraje en el Perú es un mecanismo de solución extrajudicial elegido por las partes o impuesto por la ley a las partes, con la finalidad de que un tercero independiente e imparcial designado por éstas, resuelva uno o más conflictos de manera privada, definitiva e inapelable. De otro lado, para el profesor Mario Castillo el arbitraje es una forma oficial - no estatal- de administrar justicia y su definición parte de la premisa que el arbitraje es una sustracción legalmente autorizada a la jurisdicción estatal.

Si bien en el Perú el arbitraje es la vía de solución impuesta a las partes en las controversias que surjan de la contratación pública entre un contratista y una entidad pública, pues así ha sido regulado en la legislación sobre contrataciones con el Estado; no sucede lo mismo cuando se trata de conflictos que surgen entre privados. En estos casos, las partes de una relación contractual o de otra naturaleza pueden libremente elegir al arbitraje como el mecanismo extrajudicial de solución de conflictos para lo cual deberán celebrar un convenio arbitral. Sin embargo, como hemos mencionado en la introducción del presente artículo, el arbitraje durante mucho tiempo ha sido concebido como un mecanismo de solución de conflictos reservado solo para determinados grupos o élites sociales, económicas o empresariales; ya sea por falta de conocimiento de la existencia del mismo o por los altos costos de los honorarios de los árbitros y costos administrativos arbitrales de los Centros de Arbitraje, que hacían inaccesible el arbitraje para el ciudadano

6. Un dato curioso que no constituye una práctica actual y no está contemplado expresamente en la ley vigente de arbitraje, pero que sí estaba expresamente contemplado en la comentada ley general de arbitraje derogada, era la posibilidad que en el convenio arbitral las partes designen al árbitro que resolverá la futura controversia. Considero que la falta en aquellos tiempos de oferta de árbitros hacia necesaria esta figura, sin embargo, en la actualidad si existe una comunidad de árbitros mayor, sin perjuicio de ello, nada impide que las partes hoy en día puedan incluir en su convenio arbitral la designación del árbitro. Lo que habría que analizar es su pertinencia o no. 
común, emprendedores o para las pequeñas o medianas empresas, es decir, para la mayoría de la población peruana.

Es así que permitir a los ciudadanos en general el acceso a mecanismos de solución de conflictos como el arbitraje no solo es una responsabilidad y práctica democrática de un Estado, sino que constituye también una expresión práctica de acceso a la justicia arbitral. Los ciudadanos no solo debemos tener el derecho de acceder a la justicia ordinaria - tribunales de justicia estatal - sino a la justicia arbitral - tribunales de justicia privada - pues ambos constituyen parte de nuestro sistema de administración de justicia según el artículo 139 de la Constitución Política del Perú y, por consiguiente, ambos tribunales — judicial y arbitral- ejercen función jurisdiccional con los limites o alcances legales que les corresponde. Por consiguiente, es relevante que toda persona natural o jurídica pueda ejercer su derecho a elegir si sus conflictos de naturaleza privada que versen sobre derechos de libre disposición, sean resueltos por un juez del Poder Judicial o por un tribunal arbitral.

El acceso a justicia es un principio básico de un Estado democrático y de Derecho. Por ello, los estados deben tomar las medidas necesarias para no solo regular sistemas de resolución de conflictos alternativos al proceso judicial, como el arbitraje, sino garantizar el derecho a la igualdad de acceso a la justicia arbitral para todos, incluyendo los grupos vulnerables y de menores recursos económicos.

Uno de los principales obstáculos que existían en el Perú para el acceso a la justicia arbitral eran los costos de los honorarios arbitrales, gastos arbitrales administrativos y de representación o asesoría legal. Frente a ello, uno de los retos del Estado peruano era la democratización de la justicia arbitral, permitiendo incorporar y ampliar la participación ciudadana excluida en la elección de este mecanismo, a través de regulaciones que eliminen los altos costos económicos en un arbitraje para que el ciudadano con menores recursos o el emprendedor puedan acceder a la justicia arbitral.
La finalidad de este artículo es conceptualizar el acceso a la justicia a través del arbitraje como una forma democrática que tienen las personas para resolver sus conflictos, haciendo uso de su derecho a elegir o no el sistema de justicia arbitral frente al de los tribunales judiciales.

Es así, que consideramos que la democratización del arbitraje en el Perú se viene produciendo al haber el Estado peruano tomado la decisión de regular sistemas arbitrales como el arbitraje en salud, arbitraje de consumo y el arbitraje popular que hacen posible que el arbitraje sea más accesible y conocido en distintos segmentos de la sociedad peruana antes excluidos principalmente por la falta de conocimiento de la existencia de este mecanismo extrajudicial de solución de conflictos y por los altos costos económicos que impedían su elección y acceso a la justicia arbitral.

\section{ARBITRAJE POPULAR}

El arbitraje, a pesar de haber sido creado y usado por las personas como un mecanismo de solución de conflictos incluso antes de la propia existencia del Estado y los tribunales de justicia estatal como lo conocemos hoy, es percibido en tiempos de modernidad o contemporáneos como un mecanismo de solución de controversias exclusivo o dirigido para determinadas élites económicas, grupos empresariales o para determinadas actividades comerciales. Sin embargo, con la primera disposición final del Decreto Legislativo 1071, que declara de interés nacional el acceso al arbitraje para la solución de controversias de todos los ciudadanos, el arbitraje empieza su proceso de democratización como un sistema de justicia al cual todos los peruanos puedan acceder y no solo un sector económico o social de la sociedad peruana.

Desde el año 2008 el derecho humano y constitucional de todo peruano al acceso a la justicia no se limita únicamente a los tribunales de justicia, no se circunscribe únicamente a los tribunales judiciales, sino que ahora las personas de menores recursos, pequeñas empresas - PYMES pueden acceder a un mecanismo más rápido y económico de solución de conflictos a 
través del arbitraje popular. De esta manera el Estado apuesta por la masificación de la utilización del arbitraje como un medio extrajudicial de solución de conflictos al alcance de todo ciudadano, a costos accesibles y adecuados.

Resulta interesante el quinto párrafo de la disposición final comentada que señala que el Ministerio de Justicia podrá también promover la creación de instituciones arbitrales mediante la aprobación de formularios tipo para la constitución de instituciones arbitrales en forma de asociaciones, así como reglamentos arbitrales tipo, lo que permitiría la descentralización del arbitraje popular a nivel nacional.

Es así, que mediante el Decreto Supremo Nº162008-JUS se crea el Programa de Arbitraje Popular cuya ejecución está a cargo de la Dirección de Conciliación y Medios Alternativos de Solución de Conflictos-DCMA del Ministerio de Justicia, a efectos de promover el uso masivo de este mecanismo en todos los sectores a costos razonables. Según la normatividad comentada, el arbitraje popular puede ser de derecho o equidad, $y$ es un arbitraje institucional, ya que solo puede ser organizado y administrado por el Centro de Arbitraje Arbitra Perú de la DCMA o por otras institucionales públicas o privadas con las cuales la DCMA haya celebrado convenios para la implementación del arbitraje popular.

El arbitraje popular es un mecanismo de solución de conflictos extrajudicial que tiene como objetivo que un tercero imparcial resuelva una o más controversias que versen sobre derechos disponibles de las partes, cuya cuantía de la pretensión no supere las 20 Unidades Impositivas Tributarias-UIT7, es decir, no mayor a S/ 86,000.00. ${ }^{8}$ Sin embargo, tratándose de decisiones arbitrales que se inscriban o anoten en los registros públicos, no habrá restricción de cuantía ${ }^{9}$, o cuando no sea posible determinar el monto del reclamo en forma previa al inicio del arbitraje, atendiendo a la condición económica de la parte solicitante, también podrá aceptarse el trámite.

Las partes para someter sus controversias de naturaleza contractual o extracontractual que versen sobre derechos disponibles a este tipo de arbitraje requieren la celebración de un convenio arbitral que designe a la institución arbitral que es autorizada para realizar el arbitraje popular o la designación del Centro de Arbitraje Arbitra Perú de la DCMA.

En este orden de ideas, a través del arbitraje popular se está democratizando la justicia arbitral a efectos que emprendedores o personas de menores recursos económicos puedan acceder a un mecanismo extrajudicial que les permita tener una solución rápida, ágil, económica y eficiente, sin verse obligados a transitar por el sistema de justicia tradicional lento, costoso, engorroso y muchas veces interminable; pero, además, sin verse impedidos de acceder al sistema de justicia arbitral por los altos costos del servicio.

Entre las principales características reguladas para el arbitraje popular están que es un arbitraje institucional - de Derecho- salvo que las partes acuerden que sea de conciencia; puede estar a cargo de un tribunal colegiado compuesto por tres árbitros o árbitro único; y no es necesario que las partes tengan la asistencia de un abogado. Las tarifas de los honorarios de los árbitros van desde $\mathrm{S} / 300.00$ a un máximo de $\mathrm{S} / 2,800.00$, lo que resulta comparativamente con otros Centros de Arbitraje privados tarifas muy módicas.

\section{ARBITRAJE EN CONSUMO}

El arbitraje de consumo es un mecanismo de solución de conflictos gestionado por el Es-

7. Así lo señala el artículo 4 del Estatuto del Centro de Arbitraje Popular del Ministerio de Justicia aprobado por la Resolución Ministerial № 0639-2008-JUS.

8. El valor de la UIT al 2020, año de redacción de este artículo, es de S/ 4,300.00.

9. Segundo párrafo de la primera disposición final del Decreto Legislativo 1071. 
tado, que tiene como finalidad que el consumidor y proveedor sometan de manera voluntaria la solución de un conflicto futuro o presente a la decisión de un tercero o terceros. Este sistema arbitral se presenta como una alternativa a la solución de los conflictos de consumo en la vía administrativa — INDECOPI— o en la vía judicial.

Entre las principales características del arbitraje de consumo está la gratuidad del proceso, pues el consumidor está exonerado de cualquier pago por trámite de la petición de arbitraje; la voluntariedad, pues las partes tienen libertad para someter las controversias que surjan de una relación de consumo al arbitraje; la unidireccionalidad, debido a que el arbitraje solo puede ser iniciado por el consumidor y no por el proveedor; y el antiformalismo, ya que no existen formalidades especiales en el proceso, que por lo demás puede llevarse en una audiencia única.

El Arbitraje de consumo es un sistema gestionado por el Estado a través de las Juntas Arbitrales de Consumo, que, según lo dispone el artículo 8 del Reglamento del Sistema de Arbitraje de Consumo $^{10}$, son constituidas por la Autoridad Nacional de Protección del Consumidor - INDECOPI-, en coordinación con los gobiernos regionales y locales $y$, de ser el caso, con las entidades o personas jurídicas de derecho público del lugar donde se pretenda constituirlas. Es ante estas Juntas que los consumidores podrán solicitar un arbitraje de consumo cuyo costo de trámite es gratuito y no requiere la asistencia de un abogado. Esto nos permite decir que las Juntas - a las que se pueden someter las controversias que surgen de una relación de consumo, entre consumidor y un proveedor de bienes o servicios - son una nueva alternativa extrajudicial de solución de conflictos que permite a los ciudadanos peruanos acceder a una justicia más pronta, sencilla y especializada.
Según lo dispone el artículo 13 del Reglamento comentado, cuando la cuantía de la petición o solicitud de arbitraje no supere las 3 UIT, el tribunal arbitral estará conformado por árbitro único. En caso se supere esa cuantía y exista acuerdo entre las partes, el tribunal arbitral podrá ser colegiado integrado por tres árbitros.

A diferencia de otros sistemas de arbitraje, este sistema arbitral es unidireccional, porque solo puede ser solicitado por el consumidor. El artículo 23 del Reglamento faculta a los proveedores o a las organizaciones empresariales interesadas en que las controversias con los consumidores se resuelvan a través del arbitraje de consumo a adherirse al Sistema de Arbitraje de Consumo, presentando una solicitud dirigida a la Dirección. Esta adhesión implica la oferta pública de sometimiento al arbitraje de consumo con una vigencia mínima de un año. En este sentido, conforme lo dispone el artículo 31 del Reglamento, el sometimiento al arbitraje de consumo puede acreditarse con el convenio arbitral pactado por las partes, con la presentación de una solicitud de inicio de arbitraje contra un proveedor adherido al Sistema de Arbitraje de Consumo o, una vez surgida la controversia, cuando el proveedor acepta la petición del consumidor de someter dicha controversia al arbitraje de consumo.

De otro lado, el trámite del proceso arbitral de consumo es sumamente sencillo para el usuario, pues se inicia con una petición o solicitud que podrá ser contestada por el proveedor; no requiere presentación de demanda arbitral y, por ende, tampoco contestación de ésta; hay la posibilidad que se convoque a una audiencia única y el laudo deberá ser emitido en un plazo de 45 días hábiles contados desde presentada la petición arbitral, a diferencia del reglamento derogado que establecía un plazo de 90 días.

10. El nuevo reglamento del sistema de arbitraje de consumo fue aprobado mediante Decreto Supremo $\mathrm{N}^{\circ} 103-$ 2019-PCM y tiene como objetivo reglamentar el Sistema de Arbitraje de Consumo que fue creado por lo dispuesto en el artículo 137 de la Ley 29571. Este sistema se crea con la finalidad de brindar a los consumidores una alternativa de solución de conflictos que cumpla con las características de sencillez, rapidez, gratuidad, y de carácter vinculante. 
Por todo lo expuesto, consideramos que el arbitraje de consumo coadyuva en el Perú al acceso y democratización de la justicia arbitral para los consumidores y en especial para casos de mínima cuantía.

\section{ARBITRAJE EN SALUD}

En el país, al igual que en otras partes del mundo, el sector salud es uno de los sectores más complicados por la complejidad del servicio que se presta. A menudo en este sector se generan controversias por la deficiencia o calidad del servicio prestado - tanto en la atención médica como en la administrativa - tanto en instituciones públicas como privadas - hospitales, clínicas, centros de salud, laboratorios clínicos, compañías de seguro, etc.-, así como conflictos por negligencias médicas que ponen en mayor riesgo la salud o vida de las personas afectando sus derechos humanos que el Estado debe cautelar y proteger.

Es así que la Ley General de Salud, Ley 26842, en su artículo 15, numeral 3 , inciso f), regula que toda persona tiene derecho a que se le provea de mecanismos alternativos y previos al proceso judicial para la solución de conflictos en los servicios de salud. Uno de esos mecanismos, además de la conciliación es el arbitraje. Y es en esta línea normativa que el artículo 30 del Decreto Legislativo 1158 dispone que el Centro de Conciliación y Arbitraje - CECONAR - es un órgano resolutivo que forma parte de la estructura de la Superintendencia Nacional de Salud —SUSALUD_y es competente para conocer y resolver las controversias en asuntos de salud a través de mecanismos de conciliación o arbitraje.

En ese sentido, el CECONAR es la institución arbitral encargada de tramitar los procesos arbitrales en temas de salud y también tiene la facultad de autorizar a otros Centros de Arbitra- je privados para que puedan ejercer la función arbitral en temas de salud.

De mismo modo, el artículo 31, inciso 2 del Decreto Legislativo 1158 establece como una de las competencias de CECONAR el registro y habilitación de los Centros de Conciliación y Arbitraje con especialización en salud para resolver los conflictos entre los agentes vinculados al Sistema Nacional de Salud, y entre estos y los usuarios, de conformidad con la legislación de la materia. Estos Centros, para su registro y habilitación, deberán ceñirse a los criterios y parámetros que establezca CECONAR, de modo que garanticen además de una idoneidad técnica, neutralidad e independencia, costos razonables y económicos en sus procesos, sin que constituyan una barrera de acceso para el sometimiento de controversias por las partes. En consecuencia, bajo el análisis de dicha normatividad, el arbitraje en salud es solo institucional y podrá realizarse solo en CECONAR o en un Centro de Arbitraje registrado y habilitado por el propio CECONAR.

El arbitraje en salud constituye un mecanismo de solución extrajudicial que tiene como objetivo que un tribunal arbitral - unipersonal o colegiado - resuelva de forma definitiva, inapelable y vinculante una controversia que surja entre los actores del sistema nacional de salud o entre éstos y los usuarios por la prestación de servicios de salud, o demás derechos u obligaciones relacionados o conexos.

Conforme lo dispone el artículo 33 del Decreto Legislativo 1158, el arbitraje en salud es de naturaleza voluntaria. Esto quiere decir que a efectos de que una controversia de salud pueda ser resuelta mediante arbitraje, se va a requerir la existencia de un convenio arbitral entre las partes ${ }^{11}$ que otorgue competencia al tribunal arbitral de CECONAR o de una institución habilitada por ésta, para la resolución de la controversia.

11. Según el artículo 13, numeral 1 y 2 de la Ley de Arbitraje, el convenio arbitral es un acuerdo por el que las partes deciden someter a arbitraje todas las controversias o ciertas controversias que hayan surgido o puedan surgir entre ellas respecto de una determinada relación jurídica contractual o de otra naturaleza. El convenio arbitral puede ser una cláusula incluida en un contrato o un acuerdo independiente. 
En caso exista acuerdo de las partes para someter una controversia de salud a arbitraje, pero no se haya designado a un Centro de Arbitraje, se entenderá que la institución arbitral competente es CECONAR.

De otro lado, y sin perjuicio de lo expuesto, debemos señalar que existe una excepción al sometimiento voluntario del arbitraje por las partes: cuando una de las partes es ESSALUD. En estos casos el arbitraje será obligatorio y legal -en caso no exista acuerdo entre las partes usuario y ESSALUD - para someter una controversia de salud al arbitraje. El fundamento legal está en el segundo párrafo del artículo 91 del Reglamento de la Ley de Modernización de la Seguridad Social en Salud, aprobado por el Decreto Supremo $N^{\circ} 009-97-S A$, que señala que el IPSS - ahora ESSALUD - queda sometidos al reglamento de arbitraje y solución de controversias de SEPS — ahora SUSALUD—. ${ }^{12}$

Esta obligatoriedad del arbitraje que alcanza a ESSALUD también tiene su fundamento legal en la Ley de Creación del Seguro Social de Salud, Ley 27056, que en su artículo 1 señala que ESSALUD se crea sobre la base del Instituto Peruano de Seguridad Social. Asimismo, la primera Disposición Final y Transitoria de la Ley comentada establece que toda mención al IPSS, en los dispositivos legales, normas administrativas, registros administrativos, así como en los actos y contratos en general, se entenderá referida al Seguro Social de Salud -ESSALUD - sin necesidad de trámite o de procedimiento alguno. Por consiguiente, cuando ESSALUD sea una de las partes de la controversia, el arbitraje en salud será obligatorio, ya que el convenio arbitral es de naturaleza legal, pues es la ley quien impone a las partes el sometimiento de la controversia a un proceso arbitral administrado por CECONAR.

Algunos árbitros especializados en salud consideran que la obligatoriedad del arbitraje solo tiene alcance o efectos para ESSALUD, mas no para el usuario del servicio para quien el arbitraje sería facultativo. Es decir, el usuario o afiliado podría optar por recurrir al arbitraje y renunciar a la jurisdicción de los tribunales de justicia, o no activar el arbitraje e ir al proceso judicial para la resolución de su conflicto. En cuyo caso, estaríamos frente a un arbitraje obligatorio unidireccional, algo similar al arbitraje de consumo, donde el único que puede solicitar el arbitraje es el consumidor, pero no así el proveedor. La diferencia con el arbitraje de consumo sería que éste siempre es voluntario, aun para la empresa o proveedor del servicio o bien, pues es necesaria su aceptación expresa para someter una controversia de consumo al arbitraje. Sin embargo, si bien coincido con mis colegas árbitros en que el arbitraje sería obligatorio solo para ESSALUD y no para sus usuarios o afiliados; considero también que la obligatoriedad del arbitraje al amparo del artículo 91 del Reglamento de la Ley de Modernización de la Seguridad Social en Salud, tiene alcance a otros, como las Entidades Empleadoras -empresas-, Entidad Prestadora de Salud-EPS y a los afiliados a una EPS o que reciban prestaciones de salud a través de servicios propios de su empleador, quedan igualmente sometidas al reglamento de arbitraje y solución de controversias de CECONAR. En consecuencia, todos ellos están bajo un arbitraje obligatorio o legal e institucional, y, no así, los afiliados a ESSALUD, pues la norma comentada no los señala expresamente. ${ }^{13}$

12. ESSALUD es una institución administradora de fondos de aseguramiento en salud —IAFAS_ y hasta 1999 era conocido como el Instituto Peruano de Seguridad Social —IPSS-. De otro lado, la Superintendencia Nacional de Salud — SUSALUD - es un organismo técnico especializado adscrito al Ministerio de Salud de Perú, que cuenta con autonomía técnica, funcional, administrativa, económica y financiera; y cuando fue fundada en el año 1997 su denominación era Superintendencia Prestadora de Salud -SEPS—.

13. El derogado artículo 53 de Reglamento de la Ley 29344, Ley Marco de Aseguramiento Universal en Salud, establecía que el arbitraje era facultativo para los afiliados a ESSALUD, porque al ser una entidad pública de salud es también una Institución Administradora de Fondo de Aseguramiento en Salud y el segundo párrafo del mencionado artículo derogado establecía claramente que en el caso de conflictos donde intervenga un afiliado, el 
Por otro lado, Frank García Ascencios ${ }^{14}$ considera que al igual como sucede en el Seguro Complementario de Trabajo de Riesgo-SCTR, donde el Tribunal Constitucional interpretó que no resultaba obligatorio para los trabajadores acudir al arbitraje, pero sí a las aseguradoras, tampoco resultaría obligatorio para el usuario que tiene una controversia con ESSALUD acudir al arbitraje, su sometimiento dependerá esencialmente de su voluntad de llevarlo al arbitraje o al Poder Judicial.

Es así, que a través del arbitraje en salud que tiene como ente rector a CECONAR de SUSALUD, los afiliados a las entidades públicas o privadas Administradoras de Fondos de Aseguramiento en Salud o Prestadoras de Servicios de Salud tienen una alternativa de resolución de conflictos más rápida en comparación con los procesos judiciales, porque el proceso arbitral puede tener un plazo promedio de seis meses a un año y medio. Además, los usuarios que lo requieren podrán solicitar auxilio económico de los costos procesales conforme lo dispone el numeral 5.1 del artículo 31 del Decreto Legislativo 1158.

En tal sentido, entre las principales características del arbitraje en salud tenemos que el proceso es realizado por arbitro único; es un arbitraje institucional porque solo se puede realizar en CECONAR o en un Centro de Arbitraje autorizado por éste; es voluntario, salvo en caso de ESSALUD que es obligatorio; es económico pues los costos de honorarios del árbitro van desde US\$ 100.00 a un máximo de US\$ 3,600.00; y es un arbitraje de Derecho, aunque no será necesario ni obligatorio la asistencia de un abogado. De otro lado, los arbitrajes en CECONAR están acorde con estos tiempos de modernidad, pues los procesos cuentan con expediente digital, notificaciones electrónicas y audiencias virtuales, además de permitir revisar el expediente arbitral desde el celular, algo muy útil en estos tiempos de COVID-19.

En este orden de ideas, a través del arbitraje en salud también se ingresa a un proceso de democratización de la justicia en el Perú, puesto que permite que los usuarios de los servicios de salud públicos o privados como los trabajadores dependientes o los afiliados a un seguro médico privado, laboral, vehicular, etc., puedan acceder a un mecanismo extrajudicial de solución de conflictos como es el arbitraje en salud y poder encontrar una solución a su controversia en un plazo menor a la tercera parte de un proceso judicial ordinario, sin los ritualismos y excesivas formalidades que caracterizan al sistema judicial y sobre todo a un costo más accesible, en comparación con centros de arbitraje privados cuya cuantía de gastos administrativos y honorarios arbitrales es muchas veces inaccesible para las personas de bajos o medianos recursos económicos. Pero, además es CECONAR tal vez un ejemplo de la modernización de los procesos arbitrales a través de la digitalización del expediente y las audiencias arbitrales online o virtuales que periten no solo economizar tiempo y dinero, sino mantener las distancias sociales por razones de pandemias como la de la COVID-19, sino que además sería de mucha utilidad en procesos donde las audiencias presenciales pueden colocar a una de las partes en una situación de alto riesgo.

\section{Conclusiones.}

Desde el análisis realizado en este trabajo sobre la democratización del arbitraje en el Perú, podemos concluir:

sometimiento a la jurisdicción arbitral será de carácter obligatorio para las entidades de salud y voluntario para los afiliados. Este artículo constituye un antecedente interesante a tener en cuenta.

14. Frank García Ascencios, «Arbitraje en Salud: ¿EsSalud está obligado a someterse al arbitraje administrado por el Centro de Conciliación y Arbitraje de SUSALUD?» Enfoque Derecho, 1 de junio de 2015, acceso el 31 de diciembre de 2020, https://www.enfoquederecho.com/2015/06/01/arbitraje-en-salud-essalud-esta-obligado-a-someterse-al-arbitraje-administrado-por-el-centro-de-conciliacion-y-arbitraje-de-susalud/. 
a) Que permitir a los ciudadanos en general el acceso a mecanismos de solución de conflictos como el arbitraje no solo es una responsabilidad y práctica democrática de un Estado, sino que constituye también una expresión práctica de acceso a la justicia arbitral. Los ciudadanos no solo debemos tener el derecho de acceder a la justicia ordinaria - tribunales de justicia estatal-, sino a la justicia arbitral - tribunales de justicia privada - pues ambos constituyen parte de nuestro sistema de administración de justicia según el artículo 139 de la Constitución Política del Perú.

b) Que la democratización del arbitraje en el Perú se viene produciendo al haber el Estado peruano tomado la decisión de regular sistemas arbitrales como el arbitraje en salud, arbitraje de consumo y el arbitraje popular que hacen posible que el arbitraje sea más accesible y conocido en distintos segmentos de la sociedad peruana antes excluidos principalmente por la falta de conocimiento de la existencia de este mecanismo extrajudicial de solución de conflictos y por los altos costos económicos que impedían su elección y acceso a la justicia arbitral.

c) Que estos tres sistemas de arbitraje en el Perú promovidos y gestionados desde el mismo Estado coadyuvan en el acceso y democratización de la justicia arbitral al cual tienen derecho todos los ciudadanos, y sobre todos aquellos de menores recursos económicos que ahora encuentran en estos tres tipos de arbitraje una alternativa de solución de conflictos frente al sistema tradicional de justicia que son los tribunales de justicia.

d) Que el Programa de Arbitraje Popular tiene como objetivo el promover el uso masivo del arbitraje en todos los sectores a costos razonables. Será un arbitraje institucional de derecho o equidad, conforme lo elijan las partes y la DCMA del Ministerio de Justicia estará a cargo de su implementación.

e) Que el arbitraje de consumo tiene como finalidad que el consumidor y proveedor sometan de manera voluntaria la solución de un conflicto futuro o presente a la decisión de un tribunal arbitral, este sistema arbitral se presenta como una alternativa a la solución de los conflictos de consumo en la vía administrativa - INDECOPI — o en la vía judicial y tiene entre las principales características la gratuidad del proceso, pues el consumidor está exonerado de cualquier pago por trámite de la petición de arbitraje.

f) Que a través del arbitraje en salud los afiliados a las entidades públicas o privadas Administradoras de Fondos de Aseguramiento en Salud o Prestadoras de Servicios de Salud tienen una alternativa de resolución de conflictos más rápida en comparación con los procesos judiciales porque el proceso arbitral puede tener un plazo promedio de seis meses a un año y medio; además de tener la posibilidad de que los usuarios que lo requieran puedan solicitar a CECONAR auxilio económico de los costos procesales.

g) Que, finalmente, tanto en los sistemas de arbitraje de consumo como de salud existe la posibilidad de realizarse audiencias arbitrales virtuales, y específicamente en el arbitraje en salud, se ha creado el expediente arbitral digital lo que se traduce sin dudas en ventajas para los usuarios del sistema arbitral y un ejemplo a replicar en otros tipos de arbitraje ya sea desde las instituciones públicas que promueven la democratización del arbitraje en el Perú o desde las instituciones arbitrales privados o ad hoc que también deben promover el acceso de más ciudadanos al arbitraje. 